\title{
Emodin enhances cisplatin sensitivity in non-small cell lung cancer through Pgp downregulation
}

\author{
SHUAI PENG ${ }^{1 *}$, JINCHENG WANG $^{2 *}, \mathrm{CHANG} \mathrm{LU}^{3 *}$, ZELIN XU ${ }^{3}$, \\ JING-JING CHAI ${ }^{4}$, QING KE ${ }^{5}$ and XIN-ZHOU DENG ${ }^{4,6}$

\begin{abstract}
${ }^{1}$ Department of Clinical Medicine, Fourth Clinical College; Departments of ${ }^{2}$ Clinical Medicine and
${ }^{3}$ Anesthesiology, Institute of Medicine and Nursing; ${ }^{4}$ Department of Clinical Oncology, Taihe Hospital, Hubei University of Medicine, Shiyan, Hubei 442000; ${ }^{5}$ Department of Laboratory Medicine, Qingpu Branch

Stem Cell Research, Taihe Hospital, Hubei University of Medicine, Shiyan, Hubei 442000, P.R. China
\end{abstract} \\ of Zhongshan Hospital, Fudan University, Qingpu, Shanghai 201700; ${ }^{6}$ Hubei Key Laboratory of Embryonic
}

Received May 11,2020; Accepted December 17, 2020

DOI: $10.3892 / 01.2021 .12491$

\begin{abstract}
Cisplatin resistance is one of the main causes of chemotherapy failure and tumor progression in non-small cell lung cancer (NSCLC). Emodin has been demonstrated to induce NSCLC cell apoptosis and act as a potential cancer therapeutic agent. However, whether emodin could affect NSCLC cell sensitivity toward cisplatin remains unclear. The present study aimed to determine the effect of emodin and cisplatin combination on the chemosensitivity of NSCLC cells. A549 and $\mathrm{H} 460$ cells were treated with different concentrations of cisplatin and/or emodin. Cell Counting Kit-8, fluorescence microscopy, immunofluorescence assays and flow cytometry were used to determine cell proliferation, drug efflux, DNA damage level and cell apoptosis, respectively. P-glycoprotein (Pgp) and multidrug resistance-associated protein 1 (MRP1) expression was detected by western blotting. The results demonstrated that emodin and cisplatin inhibited the proliferation of A549 and H460 cells. Furthermore, emodin inhibited the drug efflux in A549 and H460 cells in a dose-dependent manner. In addition, emodin enhanced cisplatin-induced apoptosis and DNA damage in A549 and H460 cells. Emodin also decreased Pgp expression in A549 and H460 cells in a dose-dependent manner; however, it had no effect on MRP1
\end{abstract}

Correspondence to: Dr Xin-Zhou Deng, Department of Clinical Oncology, Taihe Hospital, Hubei University of Medicine, 32 South Renmin Road, Shiyan, Hubei 442000, P.R. China

E-mail: dxz8605@whu.edu.cn

Miss Qing Ke, Department of Laboratory Medicine, Qingpu Branch of Zhongshan Hospital, Fudan University, 1158 East Park Road, Qingpu, Shanghai 201700, P.R. China

E-mail:48607508@qq.com

*Contributed equally

Key words: emodin, chemosensitivity, non-small cell lung cancer, P-glycoprotein, cisplatin expression. Taken together, the results from the present study demonstrated that emodin can increase A549 and H460 cell sensitivity to cisplatin by inhibiting Pgp expression. Emodin may therefore be considered as an effective adjuvant for cisplatin treatment.

\section{Introduction}

Lung cancer is a common malignant tumor and a leading cause of cancer-associated mortality worldwide (1). Non-small cell lung cancer (NSCLC) is the most common type of lung cancer worldwide, accounting for $80 \%$ of all lung cancer cases (2). Furthermore, $60 \%$ of patients with NSCLC are diagnosed with advanced-stage tumors (1). At present, patients with advanced or metastatic NSCLC are usually treated with platinum-based chemotherapy (3). Due to adverse effects of chemotherapy, such as neutropenia, stomatitis, mucositis, diarrhea, emesis and chemoresistance, patients with advanced NSCLC become less sensitive to chemotherapy $(4,5)$. It is therefore essential to improve the specificity of platinum-based chemotherapy and decrease its side effects in order to improve its efficiency. Numerous natural extracts, such as glycyrrhizin, 18 $\beta$-glycyrrhetinic acid and glabrin A and B, have demonstrated extensive biological activity and low toxicity in animal models of NSCLC and might therefore be considered as potential adjuvant drugs for the treatment of NSCLC (6).

Emodin (1,3,8-trihydroxy-6-methyl-anthraquinone) is a natural anthraquinone derivative extracted from the roots of Chinese rhubarb and other plants, such as buckthorn and cassia tora $(7,8)$. Emodin displays a variety of pharmacological and biological functions, including some anti-inflammatory, antibacterial and chemoprophylactic effects (9-11). In addition, previous studies have demonstrated that emodin exhibits some anticancer effects in breast, pancreatic and cervical cancers by inhibiting cancer cell proliferation and increasing cancer cell apoptosis and chemosensitization (12-14). Other studies have reported that emodin can reverse the chemoresistance in certain types of cancer, including leukemia, NSCLC and gallbladder cancer (15-17). Although certain studies have reported the effect of emodin on NSCLC chemosensitivity toward paclitaxel (17), 
the effect of emodin on NSCLC chemosensitivity toward other chemical drugs and the underlying mechanisms remain unclear.

Multidrug resistance proteins are the most important factors that cause chemoresistance, which leads to a decrease in chemotherapy efficacy and survival rate of patients with cervical, liver, breast and lung cancers (18). Members of the ATP binding cassette $(\mathrm{ABC})$ family are associated with multidrug resistance (MDR), and include P-glycoprotein (Pgp), multidrug resistance-associated protein 1 (MRP1) and MRP2 (19-21). MDR often occurs during the treatment of NSCLC, which leads most patients to eventually relapse or to the disease to progress (22). Therefore, determining adjuvant drugs that could inhibit the expression of multidrug resistance protein may improve NSCLC sensitivity to chemotherapy.

The present study investigated the effect of emodin on the chemosensitivity of A549 and H460 cells and on the expression of Pgp and MRP1, which are key proteins involved in MDR.

\section{Materials and methods}

Cell culture. The NSCLC cell lines A549 and H460 were purchased from the American Type Culture Collection. Cells were cultured in Dulbecco's modified Eagle's medium (DMEM; Gibco; Thermo Fisher Scientific, Inc.) supplemented with 10\% FBS (Biological Industries), $100 \mathrm{U} / \mathrm{ml}$ penicillin and $100 \mu \mathrm{g} / \mathrm{ml}$ streptomycin (Gibco; Thermo Fisher Scientific, Inc.) and placed at $37^{\circ} \mathrm{C}$ in a humidified atmosphere with $5 \% \mathrm{CO}_{2}$. Trypsin (0.25\%; Gibco; Thermo Fisher Scientific, Inc.) was used to passage cells once they reached $70-90 \%$ confluence.

Cell proliferation assay. Once cells reached $70-90 \%$ confluence, they were harvested and seeded into 96-well plates at the density of 2,500 cells/well and cultured for $12-24 \mathrm{~h}$ at $37^{\circ} \mathrm{C}$. Subsequently, cells were treated with emodin $(0,1,2.5,5,10$, $20,50,100,200$ and $300 \mu \mathrm{M})(17)$ and/or cisplatin $(0,1,2,4$, $6,8,10,15,20$ and $30 \mu \mathrm{M})(23)$ for $48 \mathrm{~h}$, the blank control $(0 \mu \mathrm{M})$ was treated with equal amounts of vehicle (DMSO). Cell Counting Kit-8 (CCK-8; $10 \mu \mathrm{l}$ ) reagent (Nanjing KeyGen Biotech Co., Ltd.) was added to each well and incubated for $2-4 \mathrm{~h}$ at $37^{\circ} \mathrm{C}$. Absorbance was read at $450 \mathrm{~nm}$ using a Multilabel Plate Reader (Monobind, Inc.) (24).

Western blotting. Cells were lysed with RIPA buffer $(50 \mathrm{mM}$ Tris/HCl, $150 \mathrm{mM} \mathrm{NaCl}, 1 \%$ (v/v) Nonidet P40 (NP40), 0.5\% sodium deoxycholate, $0.1 \%$ SDS and protease inhibitor; $\mathrm{pH}$ 7.4) on ice and samples were centrifuged at $10,000 \mathrm{x}$ g for $5 \mathrm{~min}$ at $4^{\circ} \mathrm{C}$. Protein concentration was measured using the BCA protein assay kit (Thermo Fisher Scientific, Inc.). Proteins were mixed with $5 \mathrm{X}$ loading buffer $(0.5 \mathrm{M}$ Tris- $\mathrm{HCl} \mathrm{pH} 6.8$, $2 \%$ SDS, $0.05 \%$ bromphenol-blue, $20 \%$ 2-mercaptoethanol and $10 \%$ glycerol) and boiled for $5 \mathrm{~min}$. Proteins were separated via SDS-PAGE (10\% gel) as previously described and transferred onto PVDF membranes (25). After blocking for $2 \mathrm{~h}$ in TBST containing $5 \%$ non-fat milk, membranes were incubated with primary antibodies against Pgp (1:1,000; Sigma-Aldrich; Merck KGaA; cat. no. P7965), MRP1 (1:1,000; Cell Signaling Technology, Inc.; cat. no. 72202) and GAPDH (1:5,000; ProteinTech Group, Inc.; cat. no. 60004-1-Ig) for overnight at $4^{\circ} \mathrm{C}$. Membranes were then incubated with the secondary antibodies, HRP-conjugated anti-rabbit IgG (1:5,000; ProteinTech Group, Inc.; cat. no. 51832-2) or HRP-conjugated anti-mouse IgG (1:5,000; ProteinTech Group, Inc.; cat. no. 51866-5) for $2 \mathrm{~h}$ at $37^{\circ} \mathrm{C}$. The signal on the membrane was detected using enhanced chemiluminescence detection kit (Thermo Fisher Scientific, Inc.). Relative expression levels were normalized to endogenous control GAPDH using ImageJ software (version 1.32; National Institutes of Health).

Cell apoptosis assay. Following treatment with emodin and/or cisplatin for $48 \mathrm{~h}$, cells were harvested and $4 \times 10^{5}$ cells were double-stained with $5 \mu 1$ Annexin V-FITC and PI solution for $10 \mathrm{~min}$ at room temperature (Absin Technologies, Inc.; cat. no. abs50001). Apoptotic cells were subsequently analyzed using a CytoFlex flow cytometer (Beckman Coulter, Inc.) the apoptotic rate was determined using CytExpert 2.3 software (Beckman Coulter, Inc.) (26).

Immunocytochemical analysis of $\gamma$-H2A.X Foci. Doublestranded DNA breaks (DSBs) induce serine phosphorylation of histone H2A.X, producing $\gamma$-H2A.X foci that are then recognized by DNA damage response pathway proteins. $\gamma$-H2A.X foci are hallmark of DSBs and are markedly enhanced in irradiated cells (27). Following cell treatment with emodin and/or cisplatin for $48 \mathrm{~h}$, cells were fixed with $4 \%$ paraformaldehyde for $20 \mathrm{~min}$, permeabilized with $0.3 \%$ Triton X-100 for $5 \mathrm{~min}$ at room temperature and blocked with $5 \%$ bovine serum albumin (Sigma-Aldrich; Merck KGaA) for $30 \mathrm{~min}$ at $37^{\circ} \mathrm{C}$. Subsequently, cells were incubated with antibodies against phospho-histone H2A.X (Ser139; 1:400; Cell Signaling Technology, Inc.; cat. no. 9718) overnight at $4^{\circ} \mathrm{C}$. Cells were then incubated with CL488-conjugated anti-rabbit IgG (1:200; ProteinTech Group, Inc.; cat. no. SA00013-2) antibody for $1 \mathrm{~h}$ at $37^{\circ} \mathrm{C}$ and were washed three times with PBS. Cells were eventually stained with DAPI (1:1,000; Sigma-Aldrich; Merck KGaA; cat. no. D9542) for 3 min at room temperature and washed with PBS three times. Cells were imaged using a fluorescence microscope (magnification, x20; Leica Microsystems $\mathrm{GmbH})$.

Fluorescence microscopy to analyze intracellular rhodamine 123 accumulation. A549 and $\mathrm{H} 460$ cells were cultured for 12-24 $\mathrm{h}$ and treated with $0,1,2.5,5,10$ and $20 \mu \mathrm{M}$ emodin for $12 \mathrm{~h}$ at $37^{\circ} \mathrm{C}$. Cells were harvested, resuspended in fresh medium, and stained with $5 \mu \mathrm{M}$ rhodamine 123 (Sigma-Aldrich; Merck KGaA) for $30 \mathrm{~min}$ at $37^{\circ} \mathrm{C}$. Cells were washed three times with PBS, and drug accumulation levels were determined by fluorescence microscopy (Leica Microsystems $\mathrm{GmbH}$ ) (28). The fluorescence intensity was determined using ImageJ software (version 1.32; National Institutes of Health).

Statistical analysis. Statistical analyses were performed using IBM SPSS Statistics 22 (SPSS, Inc.) and GraphPad Prism 5 (GraphPad Software, Inc.) software. All data are expressed as the mean \pm standard of three independent experiments. Student's t-test was used to evaluate differences between two groups. Differences between multiple groups were analyzed using two-way ANOVA followed by Tukey's post hoc test. 
A

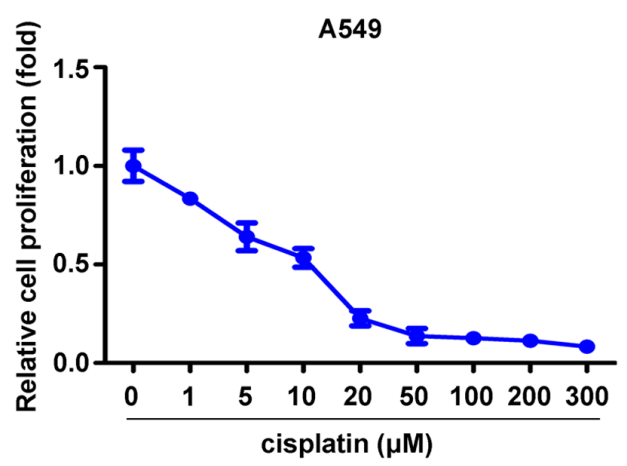

B

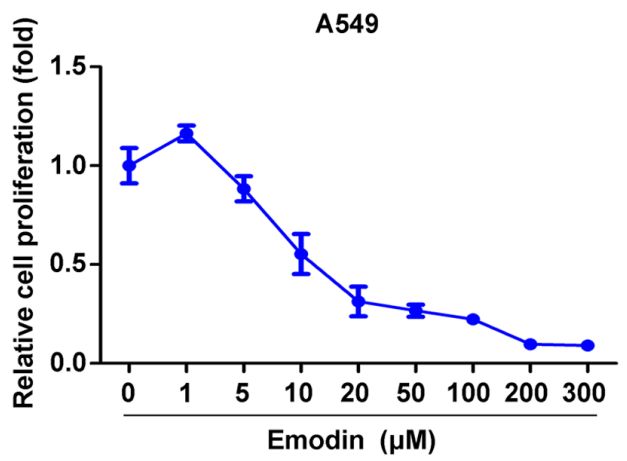

C

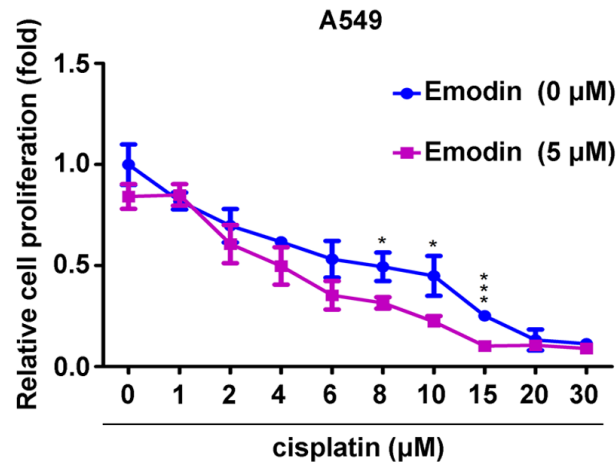

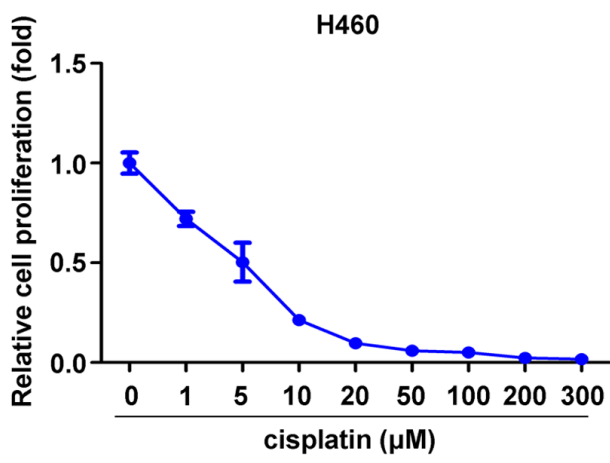
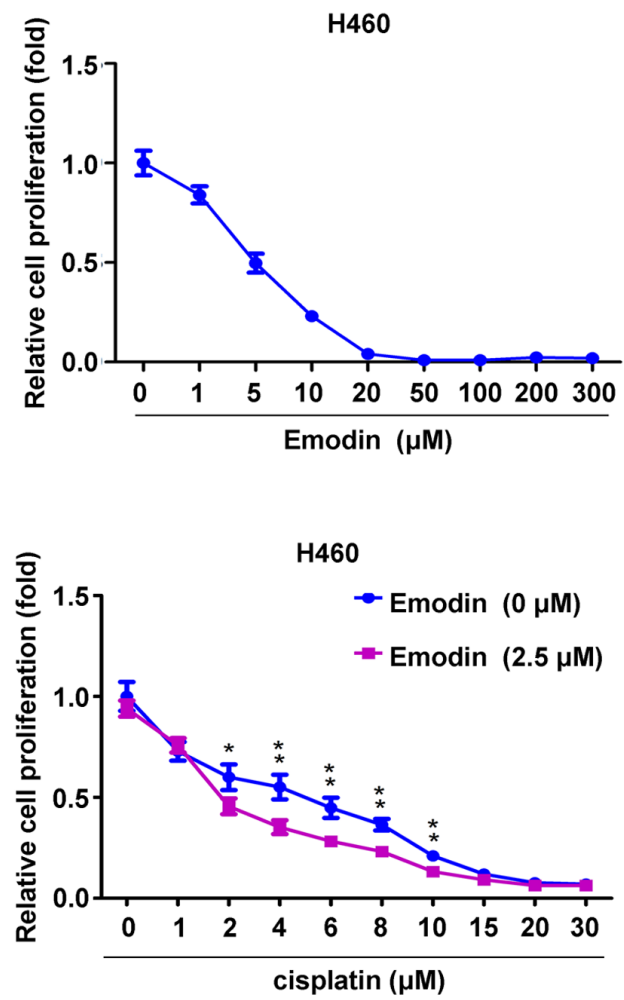

Figure 1. Effects of emodin and cisplatin on A549 and H460 cell proliferation. Cell Counting Kit-8 was used to detect A549 and H460 cell proliferation following treatment with different doses of (A) cisplatin, (B) emodin or (C) cisplatin combined with emodin for 48 h. The data are presented as the means \pm standard deviation of three independent experiments. ${ }^{*} \mathrm{P}<0.05,{ }^{* *} \mathrm{P}<0.01$ and ${ }^{* * *} \mathrm{P}<0.001$.

$\mathrm{P}<0.05$ was considered to indicate a statistically significant difference.

\section{Results}

Emodin and cisplatin inhibit A549 and H460 cell proliferation. CCK-8 assay was used to evaluate the effect of emodin and/or cisplatin on the proliferation of A549 and H460 cells. The results indicated that cisplatin and emodin at concentrations ranging from 0 to $300 \mu \mathrm{M}$ inhibited A549 and $\mathrm{H} 460$ cell proliferation in a dose-dependent manner. Notably, low dose emodin $(1 \mu \mathrm{M})$ slightly enhanced the proliferation of A549 cells, but not of H460 cells (Fig. 1A and B). The IC50 of cisplatin and emodin for A549 cells (29) was 5.25 and $13.65 \mu \mathrm{M}$, respectively, whereas the $\mathrm{IC}_{50}$ of cisplatin and emodin for H460 cells was 4.83 and $5.17 \mu \mathrm{M}$, respectively. To investigate whether emodin could be used as a cosensitizer for cisplatin, a low dose of emodin (A549 cells, $5 \mu \mathrm{M}$; H460 cells, $2.5 \mu \mathrm{M}$ ) was selected to determine its effect on cisplatin sensitization. Compared with cisplatin treatment alone, treatment with $5 \mu \mathrm{M}$ emodin significantly enhanced the anti-proliferative effect of 8,10 and $15 \mu \mathrm{M}$ cisplatin on A549 cells, whereas $2.5 \mu \mathrm{M}$ emodin significantly enhanced the anti-proliferative effect of 2, 4, 6, 8 and $10 \mu \mathrm{M}$ cisplatin on $\mathrm{H} 460$ cells (Fig. 1C). These results indicated that emodin and cisplatin may synergistically inhibit the proliferation of A549 and H460 cells.

Emodin inhibits drug efflux in A549 and H460 cells. In order to investigate the effect of emodin on the chemosensitivity of A549 and H460 cells toward cisplatin, a drug efflux experiment was performed. Briefly, A549 and H460 cells were treated with various concentrations of emodin and stained with rhodamine 123, and immunofluorescence was used to detect the intracellular accumulation of rhodamine 123 . 
A
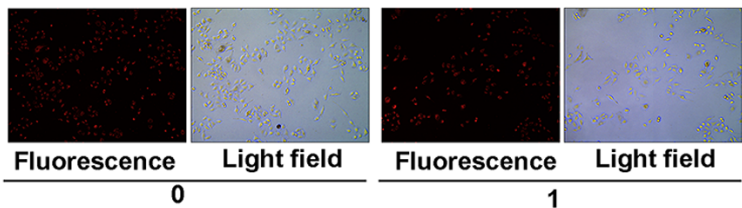

Fluorescence Light field
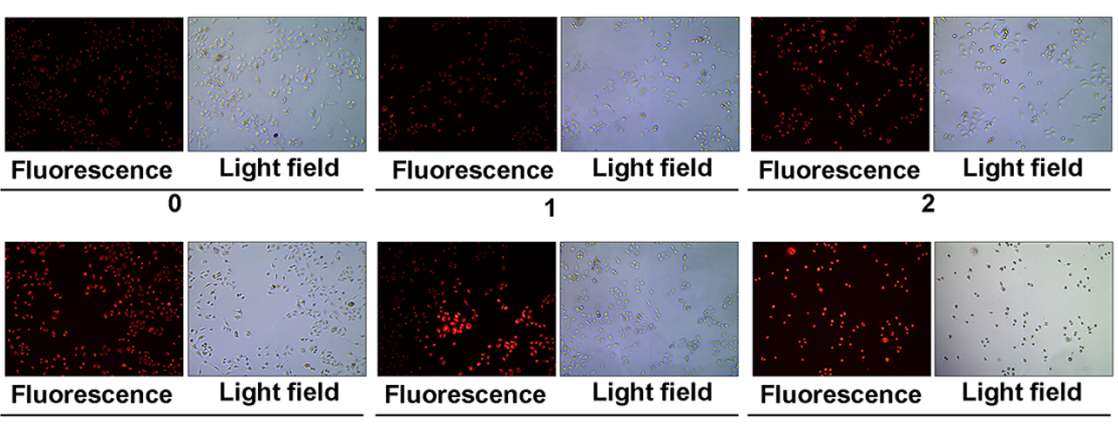

Light field

Fluorescence Light field

Fluorescence

Light field

Emodin $(\mu \mathrm{M})$

B

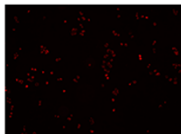

Fluorescence
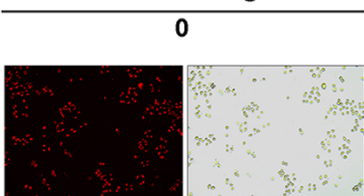

Fluorescence s

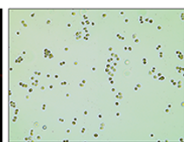

Light field

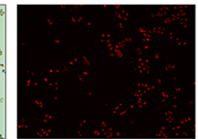
Fluorescence

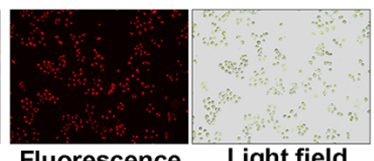

Fluorescence

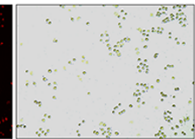

Light field 0.5
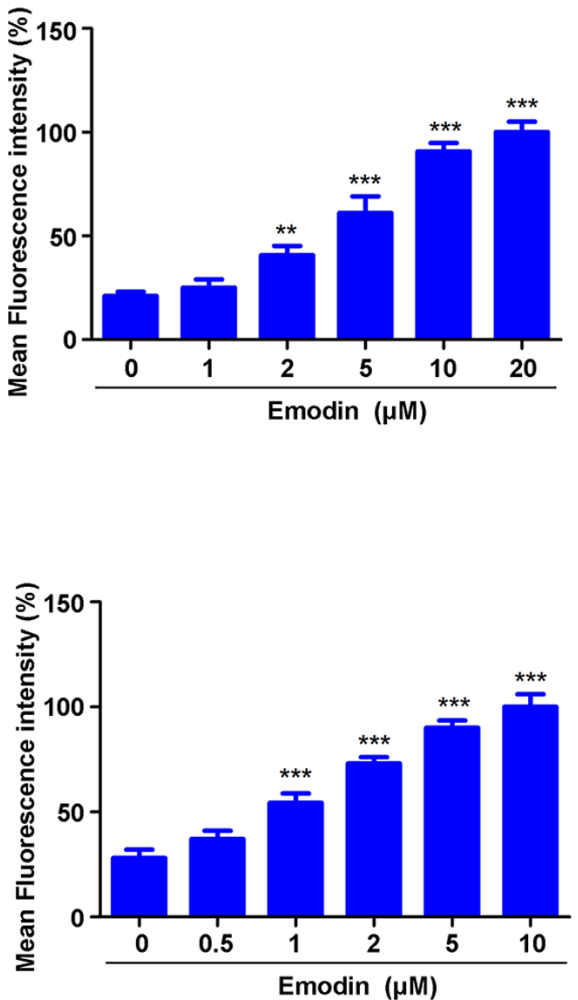

Figure 2. Effect of emodin on the drug efflux of A549 and H460 cells. Following A549 and H460 cell treatment with different concentrations of emodin for $12 \mathrm{~h}$, cells were stained with $5 \mu \mathrm{M}$ rhodamine 123 for $30 \mathrm{~min}$ and fluorescence microscopy was used to detect drug accumulation levels in (A) A549 and (B) H460 cells. ${ }^{* *} \mathrm{P}<0.01$ and ${ }^{* * * *} \mathrm{P}<0.001$.

The results demonstrated that $2,5,10$ and $20 \mu \mathrm{M}$ emodin significantly enhanced the accumulation of rhodamine 123 in A549 cells (Fig. 2A). Emodin (1, 2, 5 and $10 \mu \mathrm{M})$ also significantly enhanced rhodamine 123 accumulation in H460 cells (Fig. 2B). These data indicated that emodin may inhibit the efflux of drugs from A549 and H460 cells.

Emodin enhances cisplatin-induced apoptosis in A549 and $H 460$ cells. To investigate the effect of emodin on the chemosensitivity of A549 and H460 cells, apoptosis experiments were conducted. A549 and H460 cells were treated with emodin and/or cisplatin, and the apoptotic rate was detected by flow cytometry. The results demonstrated that $5 \mu \mathrm{M}$ emodin did not induce A549 cell apoptosis, but significantly enhanced A549 cell apoptosis induced by 5 and $10 \mu \mathrm{M}$ cisplatin (Fig. 3A). Similarly, $2.5 \mu \mathrm{M}$ emodin did not induce H460 cell apoptosis, but significantly enhanced the apoptosis of H460 cells induced by 5 and $10 \mu \mathrm{M}$ cisplatin (Fig. 3B). These results suggested that emodin may enhance cisplatin-induced apoptosis in A549 and $\mathrm{H} 460$ cells.

Emodin enhances cisplatin-induced DNA damage in A549 and $H 460$ cells. Cisplatin mainly kills tumor cells by inducing DNA damage (30). The effect of emodin on the chemosensitivity of A549 and H460 cells toward DNA damage was therefore determined through immunocytochemical analysis of $\gamma$-H2A.X foci. The results demonstrated that $5 \mu \mathrm{M}$ emodin did not induce $\gamma$-H2A.X foci formation in A549 cells but significantly enhanced $\gamma$-H2A.X foci formation in A549 cells induced by 5 and $10 \mu \mathrm{M}$ cisplatin (Fig. 4A). Similarly, $2.5 \mu \mathrm{M}$ emodin did not induce $\gamma$-H2A.X foci formation in H460 cells but significantly enhanced 5 and $10 \mu \mathrm{M}$ cisplatin-induced $\gamma$-H2A.X foci formation in H460 cells (Fig. 4B). These data indicated that emodin may increase cisplatin-induced DNA damage in A549 and H460 cells.

Emodin decreases Pgp expression in A549 and H460 cells. In order to investigate the molecular mechanism by which emodin enhances cisplatin sensitivity in A549 and H460 cells, the effect of different concentrations of emodin on the expression of Pgp and MRP1 were analyzed. The results from western blotting demonstrated that 2,5, 10 and $20 \mu \mathrm{M}$ emodin significantly decreased the expression of Pgp in A549 cells but did not affect the expression of MRP1 (Fig. 5A). Emodin (0.5, $1,2,5$ and $10 \mu \mathrm{M})$ significantly inhibited the expression of Pgp in H460 cells but did not affect the expression of MRP1 (Fig. 5B). These results suggested that emodin may inhibit MDR related protein-Pgp expression.

\section{Discussion}

Cisplatin is a common chemotherapy drug used in the treatment of various types of cancer; however, cisplatin also exhibits serious adverse effects, particularly nephrotoxicity and oxidative injury $(23,31)$. Previous studies have reported that the therapeutic efficacy of emodin combined 
A

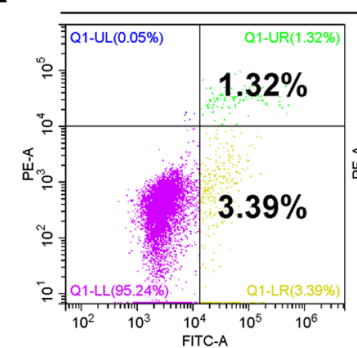

Blank

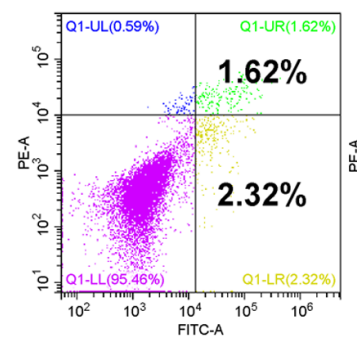

$5 \mu \mathrm{M}$ Emodin

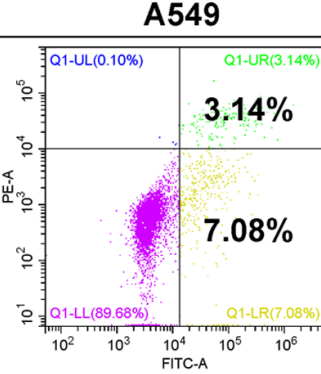

$5 \mu \mathrm{M}$ cisplatin

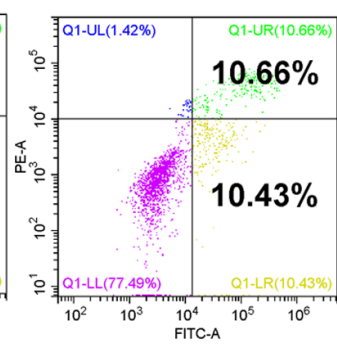

$5 \mu \mathrm{M}$ cisplatin + $5 \mu \mathrm{M}$ Emodin
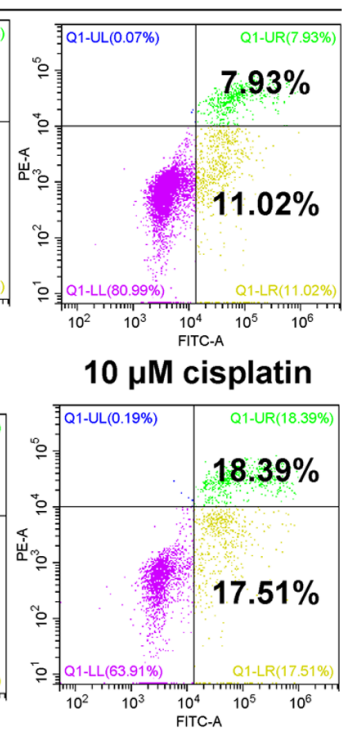

$10 \mu \mathrm{M}$ cisplatin + $5 \mu \mathrm{M}$ Emodin

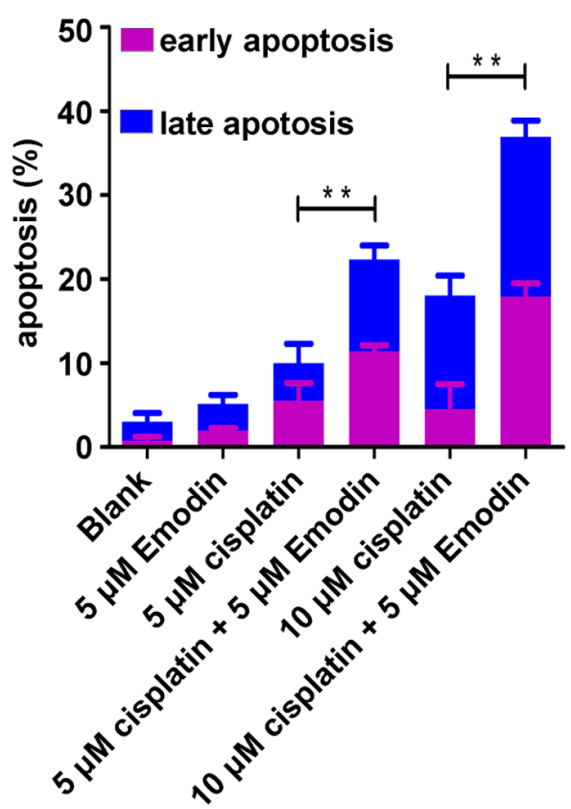

B

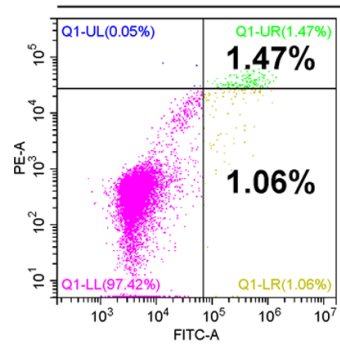

Blank

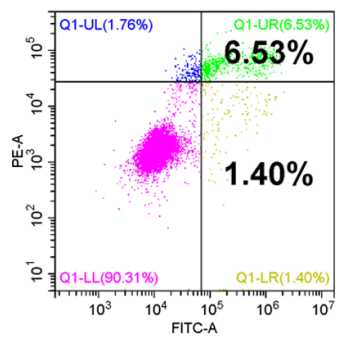

$2.5 \mu \mathrm{M}$ Emodin

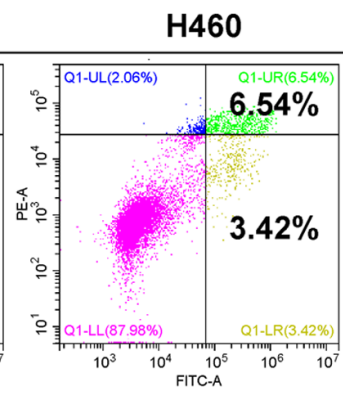

$5 \mu \mathrm{M}$ cisplatin

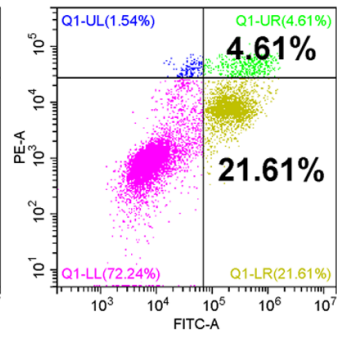

$5 \mu \mathrm{M}$ cisplatin + $2.5 \mu \mathrm{M}$ Emodin

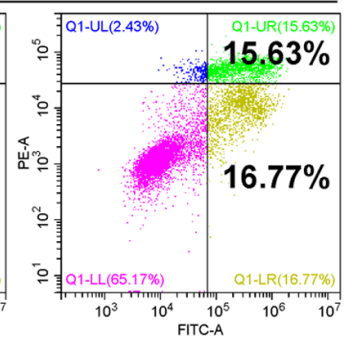

$10 \mu \mathrm{M}$ cisplatin

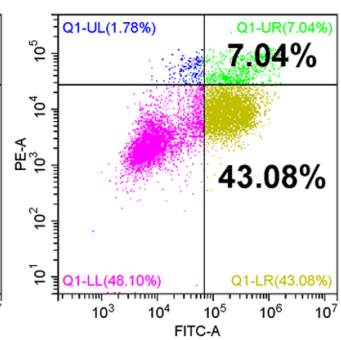

$10 \mu \mathrm{M}$ cisplatin + $2.5 \mu \mathrm{M}$ Emodin

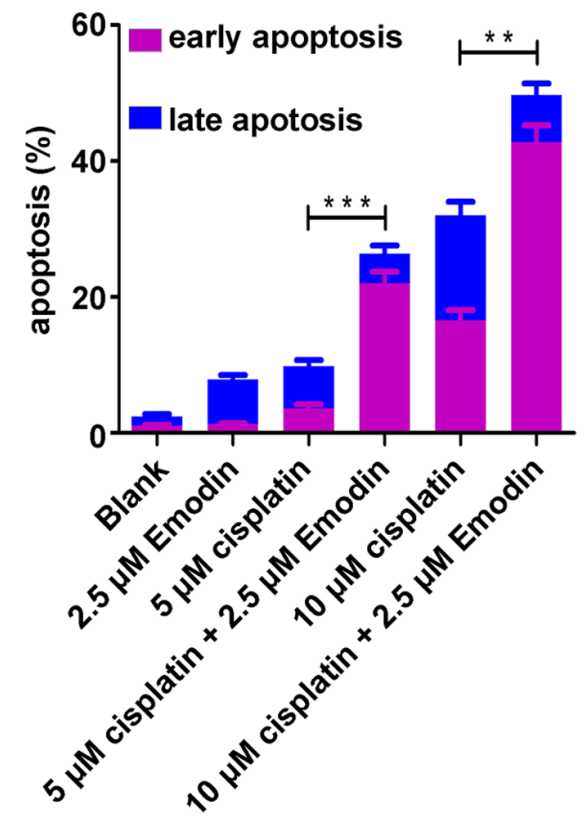

Figure 3. Effect of emodin on cisplatin-induced apoptosis in A549 and H460 cells. Following A549 and H460 cell treatment with different concentrations of emodin and/or cisplatin for $24 \mathrm{~h}$, the blank control group was treated with equal amounts of vehicle (DMSO), and cells were stained with an Annexin V-FITC/PI apoptosis detection kit, and flow cytometry was used to detect the cell apoptosis rate in (A) A549 and (B) H460 cells. ${ }^{* * *} \mathrm{P}<0.01$ and ${ }^{* * * *} \mathrm{P}<0.001$.

with chemical drugs is higher than that of chemical drugs alone, and that combination treatment also results in fewer adverse effects $(7,15,32)$. For example, emodin can enhance the therapeutic effect of gemcitabine on pancreatic cancer without other toxic effects (33). Other studies have demonstrated that emodin can increase the antitumor effect of gemcitabine even when gemcitabine is administered at a low dose $(33,34)$. Compared with treatment with cisplatin, carboplatin or oxaliplatin alone, cotreatment of emodin with cisplatin, carboplatin or oxaliplatin effectively enhances the chemosensitivity of the gallbladder cancer cell line SGC996 via glutathione depletion and MRP1 downregulation both in vitro and in vivo $(34,35)$. Therefore, the combination of emodin derived from traditional Chinese medicine and cisplatin may therefore represent a potential method to decrease the toxicity of cisplatin toward normal cells and increase its toxicity toward tumor cells.

In the present study, the effect of emodin and cisplatin on A549 and H460 cells behavior was evaluated. The results demonstrated that emodin significantly enhanced the antiproliferative, antidrug efflux, pro-apoptotic and DNA-damaging effects in combination with cisplatin in vitro. These data 
A
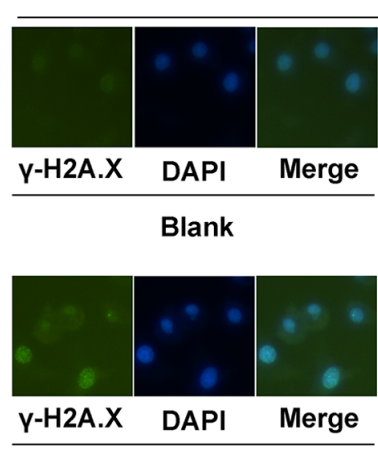

$5 \mu \mathrm{M}$ Emodin

B
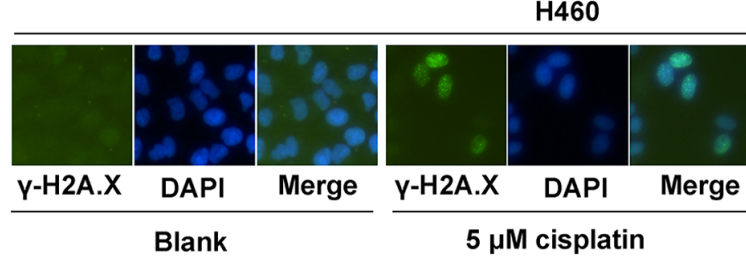

$5 \mu \mathrm{M}$ cisplatin

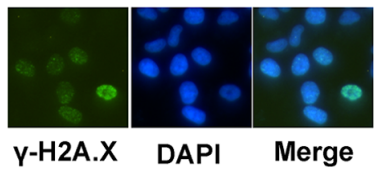

$2.5 \mu \mathrm{M}$ Emodin
A549
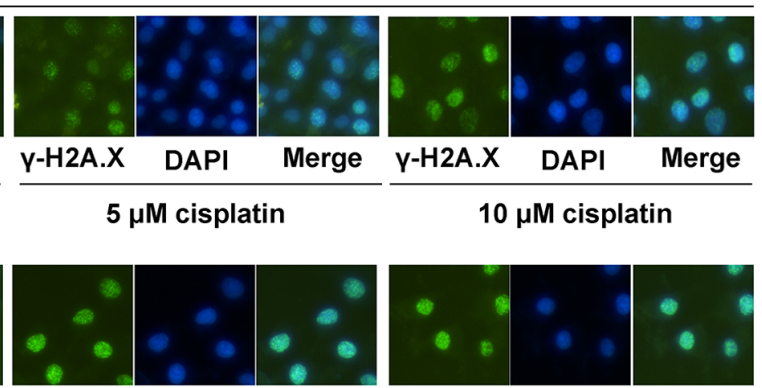

Y-H2A.X DAPI Merge $\mathrm{Y}$-H2A.X DAPI Merge

$10 \mu \mathrm{M}$ cisplatin + $5 \mu \mathrm{M}$ Emodin
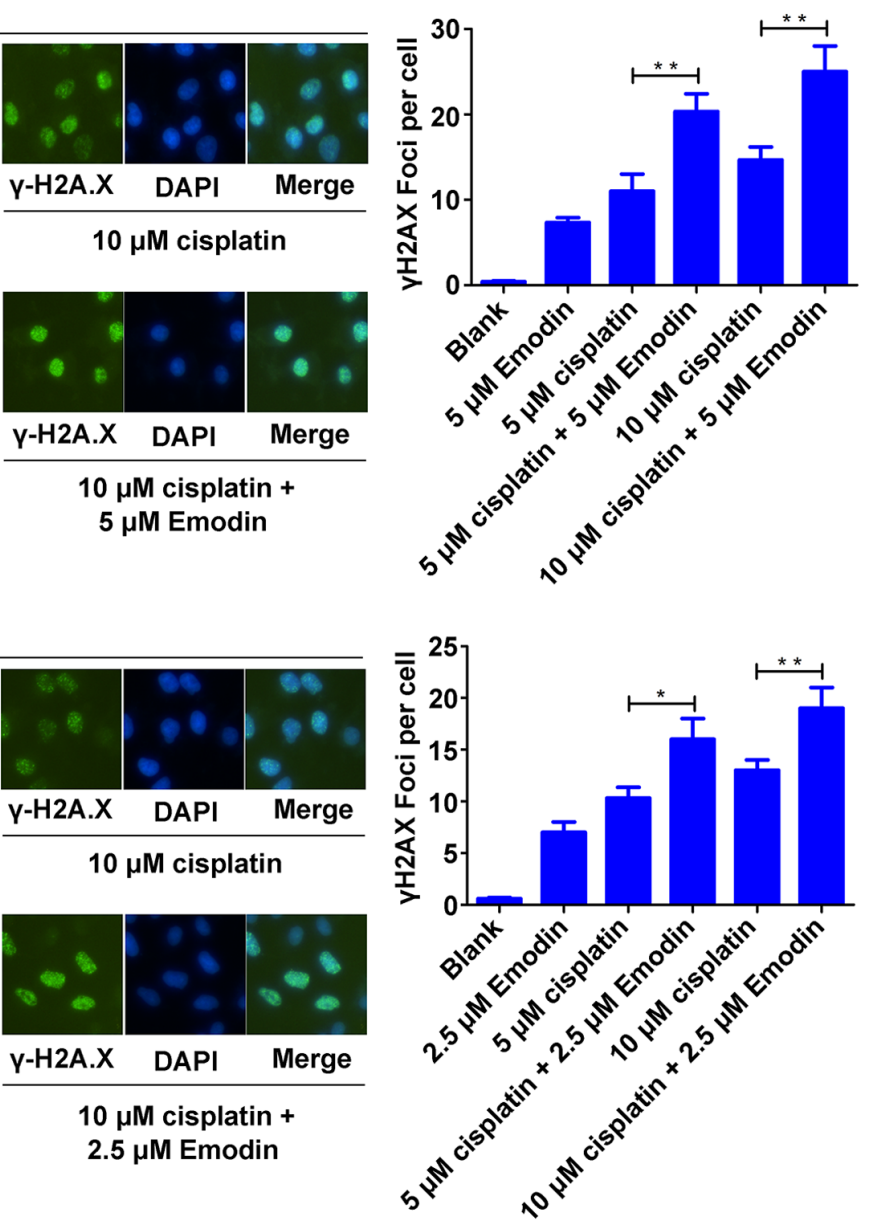

Figure 4. Effect of emodin on DNA damage in A549 and H460 cells. Following A549 and H460 cell treatment with different concentrations of emodin and/or cisplatin for $24 \mathrm{~h}$, the blank control group was treated with equal amounts of vehicle (DMSO), immunocytochemical analysis was used to analyze $\gamma$-H2A.X foci formation in (A) A549 and (B) H460 cells. ${ }^{*} \mathrm{P}<0.05$ and ${ }^{* *} \mathrm{P}<0.01$.

A

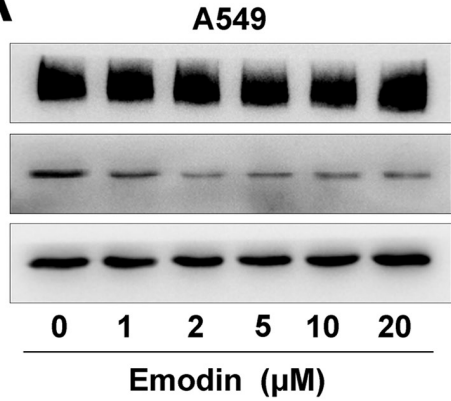

B

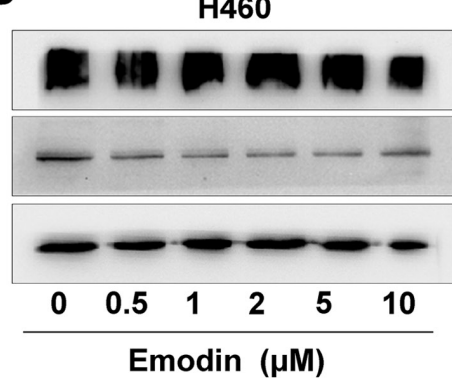

MRP1

Pgp

GAPDH

MRP1

Pgp

GAPDH

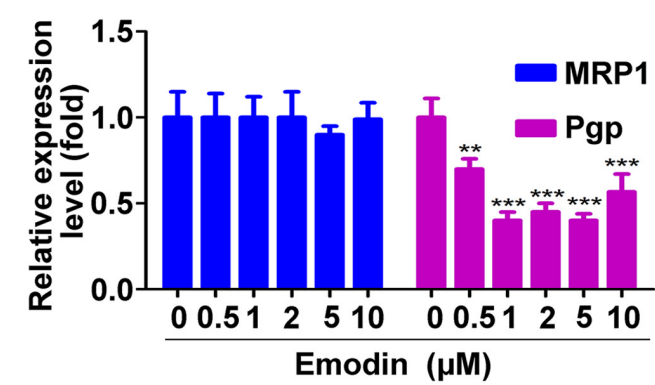

Figure 5. Effect of emodin on the expression of Pgp and MRP1 in A549 and H460 cells. Following A549 and H460 cell treatment with different concentrations of emodin for $24 \mathrm{~h}$, western blotting was used to detect Pgp and MRP1 expression in (A) A549 and (B) H460 cells. ${ }^{* *} \mathrm{P}<0.01$ and ${ }^{* * *} \mathrm{P}<0.001$. Pgp, P-glycoprotein; MRP1, multidrug resistance-associated protein 1. 
suggested that emodin may enhance cisplatin-induced antitumor activity in A549 and H460 cells in a dose-dependent manner. Previous studies have reported that $5 \mu \mathrm{M}$ emodin slightly promotes the proliferation of bladder cancer cells, although there was no significant difference $(15,32)$. In addition, emodin significantly decreases the antitumor effect of tamoxifen in HER2 $2^{+}$breast cancer cells (36). Emodin may likely show different levels of antitumor activity depending on the type of tumor and the antitumor activity of different concentrations of emodin could be different in the same tumor. In the present study, different concentrations of emodin had different effects on the proliferation of A549 cells. Emodin at $1 \mu \mathrm{M}$ had a slight promoting effect on the proliferation of A549 cells, while emodin at $>5 \mu \mathrm{M}$ significantly inhibited the proliferation of A549 cells. Different concentrations of emodin had a certain inhibitory effect on H460 cell proliferation. Therefore, emodin exerted an anti-tumor effect in a concentration-dependent manner in NSCLC.

MDR is an important defense mechanism of tumor cells against chemical drugs (37). However, multiple factors are associated with MDR, including the efflux pump mechanism of drug-resistant proteins [Pgp, MRP and lipoprotein receptorrelated protein-1 (LRP1)], the decrease in DNA topoisomerase activity, and the abnormal DNA repair (38). In particular, the drug protein pump mediated by Pgp, MRP and other drug resistance-related proteins, such as BCRP and LRP1, is the main mechanism by which tumors develop MDR (27). Previous studies have demonstrated that emodin and cisplatin alone or in combination can significantly decrease the expression of Pgp and MRP1 in bladder cancer cells $(32,35,39)$. Furthermore, emodin and doxorubicin significantly decrease the expression of Pgp and MRP1 in colon cancer cells (39). In the present study, the effect of emodin on the expression of Pgp and MRP1 in A549 and H460 cells was investigated. The results demonstrated that emodin enhanced the sensitivity of NSCLC cells toward cisplatin by decreasing the expression of Pgp but not of MRP.

The present study did have some limitations. First, the effect of emodin on the mRNA expression of Pgp and MRP1 in A549 and H460 cells, and the effect of emodin on the expression of Pgp and MRP1 in combination with cisplatin, were not investigated. These topics need to be investigated in future. Secondly, the present study did not investigate the effect of emodin on the chemotherapy sensitivity of NSCLC cells in xenograft animal models. Although emodin/cisplatin administration has been found to have no significant effect on body weight and histological findings in treated mice (tissue structure, cell morphology and vascular distribution) (32), this does not imply that emodin is not toxic. Future work will perform pharmacodynamic, acute toxicity, long-term toxicity and irritability tests in order to verify the safety of emodin. To the best of our knowledge, there is currently no clinical study on the combination of cisplatin and emodin. Clinical trials and long-term follow-up are needed to fully assess the toxicity of combination therapy in the future.

In summary, the present study demonstrated that emodin could increase the sensitivity of A549 and H460 cells to cisplatin by downregulating Pgp expression. The results suggested that emodin may be considered as an effective sensitizer for cisplatin-based chemotherapy in patients with NSCLC.

\section{Acknowledgements}

Not applicable.

\section{Funding}

The present study was supported by the National Natural Science Foundation of China (grant nos. 81802997, 81602391 and 81502666); the Students' Innovation and Entrepreneurship Training Program of Hubei University of Medicine (grant no. S201910929006), the Foundation for Free Exploration of Hubei University of Medicine (grant no. FDFR201802); the Natural Science Foundation of Hubei Province of China (grant nos. 2019CFA034, 2017CFB167, 2018CFB405 and 2017CFB456) and the Scientific and Technological Project of Shiyan City of Hubei Province (grant no. 19Y40).

\section{Availability of data and materials}

Not applicable.

\section{Authors' contributions}

XZD and QK designed the present study. SP, JW and CL performed all the experiments, analyzed the data and prepared the figures. XD and ZX were responsible for the initial manuscript and interpretation of data. JJC was involved in drafting the manuscript, analysis and interpretation of data. All authors read and approved the final version.

\section{Ethics approval and consent to participate}

Not applicable.

\section{Patient consent for publication}

Not applicable.

\section{Competing interests}

The authors declare that they have no competing interests.

\section{References}

1. Romaszko AM and Doboszyńska A: Multiple primary lung cancer: A literature review. Adv Clin Exp Med 27: 725-730, 2018

2. Cheema PK, Rothenstein J, Melosky B, Brade A and Hirsh V: Perspectives on treatment advances for stage III locally advanced unresectable non-small-cell lung cancer. Curr Oncol 26: 37-42, 2019.

3. Driesen P, Lambrechts M, Kraaij K, Soldatenkova V, Chouaki N and Colinet B: A phase II single-arm study of induction chemotherapy with cisplatin and gemcitabine followed by concurrent cisplatin and gemcitabine with thoracic radiation for unresectable locally advanced non-small cell lung cancer. Ther Adv Med Oncol 5: 159-168, 2013.

4. Baldini E, Tibaldi C and Delli Paoli C: Chemo-radiotherapy integration in unresectable locally advanced non-small-cell lung cancer: A review. Clin Transl Oncol 22: 1681-1686, 2020.

5. Hauner K, Maisch P and Retz M: Side effects of chemotherapy. Urologe A 56: 472-479, 2017 (In German).

6. Pastorino G, Cornara L, Soares S, Rodrigues F and Oliveira MBPP Liquorice (Glycyrrhiza glabra): A phytochemical and pharmacological review. Phytother Res 32: 2323-2339, 2018.

7. Wei WT, Lin SZ, Liu DL and Wang ZH: The distinct mechanisms of the antitumor activity of emodin in different types of cancer (Review). Oncol Rep 30: 2555-2562, 2013. 
8. Li X, Shan C, Wu Z, Yu H, Yang A and Tan B: Emodin alleviated pulmonary inflammation in rats with LPS-induced acute lung injury through inhibiting the mTOR/HIF-1 $\alpha /$ VEGF signaling pathway. Inflamm Res 69: 365-373, 2020.

9. Xu C, Zhang J, Liu J, Li Z, Liu Z, Luo Y, Xu Q, Wang M, Zhang G, Wang F, et al: Proteomic analysis reveals the protective effects of emodin on severe acute pancreatitis induced lung injury by inhibiting neutrophil proteases activity. J Proteomics 220: 103760, 2020.

10. Ma W, Liu C, Li J, Hao M, Ji Y and Zeng X: The effects of aloe emodin-mediated antimicrobial photodynamic therapy on drugsensitive and resistant Candida albicans. Photochem Photobiol Sci 19: 485-494, 2020.

11. Chen Q, Li KT, Tian S, Yu TH, Yu LH, Lin HD and Bai DQ: Photodynamic therapy mediated by aloe-emodin inhibited angiogenesis and cell metastasis through activating MAPK signaling pathway on HUVECs. Technol Cancer Res Treat 17: $1533033818785512,2018$.

12. Zu C, Qin G, Yang C, Liu N, He A, Zhang M and Zheng X: Low dose Emodin induces tumor senescence for boosting breast cancer chemotherapy via silencing NRARP. Biochem Biophys Res Commun 505: 973-978, 2018.

13. Fu M, Tang W, Liu JJ, Gong XQ, Kong L, Yao XM, Jing M, Cai FY, Li XT and Ju RJ: Combination of targeted daunorubicin liposomes and targeted emodin liposomes for treatment of invasive breast cancer. J Drug Target 28: 245-258, 2020.

14. Akev N, Candoken E and Erdem Kuruca S: Comparative study on the anticancer drug potential of a lectin purified from aloe vera and aloe-emodin. Asian Pac J Cancer Prev 21: 99-106, 2020.

15. Wang W, Sun Y, Li X, Li H, Chen Y, Tian Y, Yi J and Wang J: Emodin potentiates the anticancer effect of cisplatin on gallbladder cancer cells through the generation of reactive oxygen species and the inhibition of survivin expression. Oncol Rep 26: $1143-1148,2011$.

16. Chen Y, Gan D, Huang Q, Luo X, Lin D and Hu J: Emodin and Its combination with cytarabine induce apoptosis in resistant acute myeloid leukemia cells in vitro and in vivo. Cell Physiol Biochem 48: 2061-2073, 2018

17. Chen S, Zhang Z and Zhang J: Emodin enhances antitumor effect of paclitaxel on human non-small-cell lung cancer cells in vitro and in vivo. Drug Des Devel Ther 13: 1145-1153, 2019.

18. Holford J, Beale PJ, Boxall FE, Sharp SY and Kelland LR: Mechanisms of drug resistance to the platinum complex ZD0473 in ovarian cancer cell lines. Eur J Cancer 36: 1984-1990, 2000.

19. Shi B, Xu FF, Xiang CP, Jia R, Yan $\mathrm{CH}$, Ma SQ, Wang $\mathrm{N}$, Wang AJ and Fan P: Effect of sodium butyrate on ABC transporters in lung cancer A549 and colorectal cancer HCT116 cells. Oncol Lett 20: 148, 2020.

20. Tian J, Hu J, Liu G, Yin H, Chen M, Miao P, Bai P and Yin J: Altered Gene expression of $\mathrm{ABC}$ transporters, nuclear receptors and oxidative stress signaling in zebrafish embryos exposed to CdTe quantum dots. Environ Pollut 244: 588-599, 2019.

21. Sauerborn Klobucar R, Zaja R, Franjević D, Brozović A and Smital T: Presence of ecotoxicologically relevant Pgp and MRP transcripts and proteins in Cyprinid fish. Arh Hig Rada Toksikol 61: 175-182, 2010

22. Zhou J, Li Z, Li J, Gao B and Song W: Chemotherapy resistance molecular mechanism in small cell lung cancer. Curr Mol Med 19: $157-163,2019$

23. Huang Y, Lei L and Liu Y: Propofol improves sensitivity of lung cancer cells to cisplatin and its mechanism. Med Sci Monit 26: e919786, 2020.

24. Deng X, Hu Y, Ding Q, Han R, Guo Q, Qin J, Li J, Xiao R, Tian S, $\mathrm{Hu} \mathrm{W}$, et al: PEG10 plays a crucial role in human lung cancer proliferation, progression, prognosis and metastasis. Oncol Rep 32: 2159-2167, 2014.
25. Deng X, Tu Z, Xiong M, Tembo K, Zhou L, Liu P, Pan S, Xiong J, Yang X, Leng J, et al: Wnt5a and CCL25 promote adult T-cell acute lymphoblastic leukemia cell migration, invasion and metastasis. Oncotarget 8: 39033-39047, 2017.

26. Dong X, Luo Z, Wang Y, Meng L, Duan Q, Qiu L, Peng F and Shen L: Altered O-glycosylation is associated with inherent radioresistance and malignancy of human laryngeal carcinoma. Exp Cell Res 362: 302-310, 2018.

27. Xiao L, Tsutsui T and Miwa N: The lipophilic vitamin C derivative, 6-o-palmitoylascorbate, protects human lymphocytes, preferentially over ascorbate, against X-ray-induced DNA damage, lipid peroxidation, and protein carbonylation. Mol Cell Biochem 394: 247-259, 2014

28. Dong W, Liao ZG, Zhao GW, Guan XJ, Zhang J, Liang XL and Yang M: Reversal effect of oxypeucedanin on P-glycoproteinmediated drug transport. Molecules 23: 1841, 2018.

29. Hurtado M, Sankpal UT, Chhabra J, Brown DT, Maram R, Patel R, Gurung RK, Simecka J, Holder AA and Basha R: Copper-tolfenamic acid: Evaluation of stability and anti-cancer activity. Invest New Drugs 37: 27-34, 2019.

30. Yang Y, Adebali O, Wu G, Selby CP, Chiou YY, Rashid N, Hu J, Hogenesch JB and Sancar A: Cisplatin-DNA adduct repair of transcribed genes is controlled by two circadian programs in mouse tissues. Proc Natl Acad Sci USA 115: E4777-E4785, 2018.

31. Shah N, Liu Z, Tallman RM, Mohammad A, Sprowls SA, Saralkar PA, Vickers SD, Pinti MV, Gao W and Lockman PR: Drug resistance occurred in a newly characterized preclinical model of lung cancer brain metastasis. BMC Cancer 20: 292, 2020.

32. Li X, Wang H, Wang J, Chen Y, Yin X, Shi G, Li H, Hu Z and Liang X: Emodin enhances cisplatin-induced cytotoxicity in human bladder cancer cells through ROS elevation and MRP1 downregulation. BMC Cancer 16: 578, 2016.

33. Liu A, Chen H, Tong H, Ye S, Qiu M, Wang Z, Tan W, Liu J and Lin S: Emodin potentiates the antitumor effects of gemcitabine in pancreatic cancer cells via inhibition of nuclear factor- $\kappa \mathrm{B}$. Mol Med Rep 4: 221-227, 2011.

34. Lin SZ, Wei WT, Chen H, Chen KJ, Tong HF, Wang ZH, Ni ZL, Liu HB, Guo HC and Liu DL: Antitumor activity of emodin against pancreatic cancer depends on its dual role: Promotion of apoptosis and suppression of angiogenesis. PLoS One 7: e42146, 2012.

35. Wang W, Sun YP, Huang XZ, He M, Chen YY, Shi GY, Li H, Yi J and Wang J: Emodin enhances sensitivity of gallbladder cancer cells to platinum drugs via glutathion depletion and MRP1 downregulation. Biochem Pharmacol 79: 1134-1140, 2010.

36. Tseng HS, Wang YF, Tzeng YM, Chen DR, Liao YF, Chiu HY and Hsieh WT: Aloe-emodin enhances tamoxifen cytotoxicity by suppressing Ras/ERK and PI3K/mTOR in breast cancer cells Am J Chin Med 45: 337-350, 2017.

37. Jiang X, Lei $\mathrm{T}$ and Zhang M: Expression and functions of formyl peptide receptor 1 in drug-resistant bladder cancer. Technol Cancer Res Treat 17: 1533034618769413, 2018.

38. Lee $\mathrm{CH}$ : Reversing agents for ATP-binding cassette drug transporters. Methods Mol Biol 596: 325-340, 2010.

39. Iyer VV, Priya PY and Kangeyavelu J: Effects of increased accumulation of doxorubicin due to emodin on efflux transporter and LRP1 expression in lung adenocarcinoma and colorectal carcinoma cells. Mol Cell Biochem 449: 91-104, 2018.

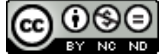

This work is licensed under a Creative Commons Attribution-NonCommercial-NoDerivatives 4.0 International (CC BY-NC-ND 4.0) License. 